Research Article

\title{
Crack Width and Load-Carrying Capacity of RC Elements Strengthened with FRP
}

\author{
Justas Slaitas $(\mathbb{D}$, Mykolas Daugevičius, Juozas Valivonis, and Tatjana Grigorjeva \\ Department of Reinforced Concrete Structures and Geotechnics, Vilnius Gediminas Technical University, \\ LT-10223 Vilnius, Lithuania \\ Correspondence should be addressed to Justas Slaitas; justas.slaitas@vgtu.lt
}

Received 7 March 2018; Revised 16 May 2018; Accepted 7 June 2018; Published 11 July 2018

Academic Editor: Young Hoon Kim

Copyright (C) 2018 Justas Slaitas et al. This is an open access article distributed under the Creative Commons Attribution License, which permits unrestricted use, distribution, and reproduction in any medium, provided the original work is properly cited.

\begin{abstract}
The present study focuses on a prediction of crack width and load-carrying capacity of flexural reinforced concrete (RC) elements strengthened with fibre-reinforced polymer (FRP) reinforcements. Most studies on cracking phenomena of FRP-strengthened RC structures are directed to empirical corrections of crack-spacing formula given by design norms. Contrary to the design norms, a crack model presented in this paper is based on fracture mechanics of solids and is applied for direct calculation of flexural crack parameters. At the ultimate stage of crack propagation, the load-carrying capacity of the element is achieved; therefore, it is assumed that the load-carrying capacity can be estimated according to the ultimate crack depth (directly measuring concrete's compressive zone height). An experimental program is presented to verify the accuracy of the proposed model, taking into account anchorage and initial strain effects. The proposed analytical crack model can be used for more precise predictions of flexural crack propagation and load-carrying capacity.
\end{abstract}

\section{Introduction}

Retrofitting of existing structures is one of the main challenges for civil engineers today. One of the most advantageous material types for strengthening is fibre-reinforced polymers (FRP) due to their corrosion resistance and high strength to low weight ratio [1-5]. Anticorrosion properties are particularly relevant in aggressive environments, for example, bridge structures [6]. Strength properties could be used even more efficiently and economically by prestressing the FRP material $[7,8]$. However, the effectiveness of strengthening can be compromised by loss of composite action, which can be delayed by using the additional anchorage [9]. There is a large quantity of researches made on the behaviour of the joint of concrete and FRP material [10-14], and the bond stiffness-reduction techniques are proposed [15-17], but none of the researches analysed by the authors was applied for prediction of concrete crack propagation. In accordance with design provisions $[18,19]$, the cracks in concrete open when a limiting tensile strain of concrete is reached; therefore, the crack width can be calculated by multiplying the mean values of a difference between tensile reinforcement and concrete strains with crack spacing. The researchers working on cracking phenomena of FRP-strengthened structures are trying to correct the empirical formulas to calculate crack spacing given by the design norms [20-22]. A different approach is proposed in this paper, that is, a crack model for direct calculation of flexural crack parameters which neglect the crack spacing. At the ultimate stage of crack propagation, the load-carrying capacity of the element is achieved. Therefore, it is assumed that the load-carrying capacity can be estimated according to ultimate crack depth (directly measuring concrete's compressive zone height). The experimental program is presented to verify the accuracy of proposed crack propagation model, taking into account anchorage and initial strain effects. An extended database is used for comparison of numerical and experimental results of crack width under service load and loadcarrying capacity of the element. In total, 98 RC beams, strengthened with externally bonded (EBR) and near 
surface-mounted (NSM) carbon fibre-reinforced polymer (CFRP) and glass fibre-reinforced polymer (GFRP) sheets, plates, strips, and rods were tested. The experimental results were collected from different scientific publications.

\section{Analytical Model}

2.1. Crack Width according to Design Standards. In this chapter, the estimation methods of the crack width and the mean crack spacing proposed in design standards $[18,19]$ are presented. The crack width of a RC structure can be calculated by following equation proposed in EC2 [18].

$$
w_{\mathrm{EC} 2}=s_{\mathrm{r} \cdot \max }\left(\varepsilon_{\mathrm{sm}}-\varepsilon_{\mathrm{cm}}\right),
$$

where $s_{\text {r.max }}$ is the maximum crack spacing and $\varepsilon_{\text {sm }}$ and $\varepsilon_{\mathrm{cm}}$ are the mean strains in reinforcement and in concrete between cracks, respectively.

The mean value of crack spacing can be defined as follows [18]:

$$
s_{\mathrm{r} . \mathrm{m}}=\frac{S_{\mathrm{r} . \mathrm{max}}}{1.7}=2 c+\frac{0.25 k_{1} k_{2} \phi}{\rho_{\mathrm{p} . \mathrm{eff}}},
$$

where $k_{1}$ is a coefficient which evaluates the bond properties of the bonded reinforcement: 0.8 for high bond bars and 1.6 for bars with an effectively plain surface (e.g., prestressing tendons); $k_{2}$ is a coefficient which takes into account the distribution of strain: 0.5 for bending and 1.0 for pure tension.

Assuming stabilized cracking, the characteristic value of the crack width of FRP-strengthened RC structures is calculated according to fib bulletin 14 [19] recommendations:

$$
w_{\mathrm{FIB}}=1.7 s_{\text {r.m }} \zeta \varepsilon_{2},
$$

where $\zeta$ is a tension-stiffening coefficient and $\varepsilon_{2}$ is the reinforcement strain in the fully cracked state.

The mean crack spacing, taking into account the effect of both the internal and the external reinforcement, can be calculated as [19]

$$
\begin{aligned}
s_{\text {r.m }} & =\frac{2 f_{\mathrm{ctm}} A_{\text {c.eff }}}{\tau_{\mathrm{sm}} u_{\mathrm{s} 1}} \frac{E_{\mathrm{s} 1} A_{\mathrm{s} 1}}{E_{\mathrm{s} 1} A_{\mathrm{s} 1}+\xi_{b} E_{f} A_{f}} \\
& =\frac{2 f_{\mathrm{ctm}} A_{\mathrm{c} . \mathrm{eff}}}{\tau_{\mathrm{fm}} u_{f}} \frac{\xi_{b} E_{f} A_{f}}{E_{\mathrm{s} 1} A_{\mathrm{s} 1}+\xi_{b} E_{f} A_{f}},
\end{aligned}
$$

where $f_{\mathrm{ctm}}$ is a mean value of concrete tensile strength; $A_{\text {c.eff }}$ is an effective area of concrete's tensile zone; $A_{\mathrm{s} 1}$ and $A_{f}$ are the areas of steel and FRP reinforcements, respectively; $E_{\mathrm{s} 1}$ and $E_{f}$ are the elasticity modules of steel and FRP reinforcements, respectively; $u_{s 1}$ and $u_{f}$ are the bond perimeters of steel and FRP reinforcement, respectively; $\tau_{\text {sm }}=1.8 f_{\mathrm{ctm}}$ and $\tau_{\mathrm{fm}}=1.25 f_{\mathrm{ctm}}$ are the mean bond stresses of steel and FRP reinforcement; and $\xi_{b}$ is a bond parameter given as

$$
\xi_{b}=\frac{\tau_{\mathrm{fm}} E_{\mathrm{s} 1} A_{\mathrm{s} 1} u_{f}}{\tau_{\mathrm{sm}} E_{f} A_{f} u_{\mathrm{s} 1}} .
$$

Neglecting the tension-stiffening effect and initial strain, the characteristic crack width is as follows [19]:

$$
w_{\mathrm{FIB} 2}=2.1 \rho_{\text {c.eff }} \frac{M_{a}}{E_{\mathrm{s} 1} d \rho_{\mathrm{eq}}} \frac{1}{\left(u_{\mathrm{s} 1}+0.694 u_{f}\right)},
$$

where $M_{a}$ is the acting moment in a cross-section, $\rho_{\text {c.eff }}$ is a ratio of the effective area in tension, and $\rho_{\mathrm{eq}}$ is the equivalent reinforcement ratio.

Hence, a denser cracking and the smaller crack widths are obtained for RC beams strengthened with FRP; the crack widths estimated by the methodology proposed in [19] were used for further analysis.

\subsection{Proposed Methodology}

2.2.1. Crack Width. In accordance with Jokūbaitis and Juknevičius and Jokūbaitis et al.'s $[23,24]$ proposed crack development model for RC structures, a flexural reinforced concrete element crack has two peaks; one leads to the crack spread toward the beam neutral axis, and the other refers to the tensile reinforcement. The width of the crack apex closer to the neutral axis is critical for further crack spread. The bond strength of concrete and reinforcements, which is equal to the tensile strength of concrete $\left(f_{\mathrm{ct}}\right)$, stresses of FRP, and steel reinforcements ( $\sigma_{s}$ and $\sigma_{f}$, respectively), resist crack propagation. Parts of the element separated by the crack rotates about the intersection point of the crack surface and neutral axis (see Figure 1(a)).

The proposed crack model is presented in Figure 1(a), where $A_{s 1}, A_{\mathrm{s} 2}$, and $A_{f}$ are the inner tensile, compressive steel, and external FRP reinforcements, respectively; $d_{1}$ and $d_{2}$ are the distances to centroids of inner reinforcements; $h_{\mathrm{cr}}$ and $h_{\mathrm{ct}}$ are the crack depth and the depth of tensile zone above it, respectively; and $w_{\mathrm{cr}}$ and $\delta_{\mathrm{cr}}$ are the crack width and the critical width of a normal crack tip, respectively. Strain distribution in a cross-section is reflected in Figure 1(b), where $x_{e}$ is a depth of compression zone of concrete; $\varepsilon_{\text {ctu }}$ and $\varepsilon_{f}$ are the ultimate tensile strain of concrete and the FRP strain, respectively. The crack depth and width dependence can be expressed from a condition of similarity of triangles:

$$
\frac{\delta_{\mathrm{cr}}}{w_{\mathrm{cr}}} \approx \frac{h_{\mathrm{ct}}}{h_{\mathrm{cr}}} \approx \frac{\varepsilon_{\mathrm{ctu}}}{\varepsilon_{f}} .
$$

General expression of ultimate value of concrete's tensile strain is used for analysis:

$$
\varepsilon_{\mathrm{ctu}}=\frac{f_{\mathrm{ctm}}}{v_{\mathrm{pl}} E_{\mathrm{cm}}} \approx \frac{2 f_{\mathrm{ctm}}}{E_{\mathrm{cm}}},
$$

where $v_{\mathrm{pl}}$ is concrete plasticity factor $\left(\nu_{\mathrm{pl}} \approx 0.5\right) ; E_{\mathrm{cm}}$ is a secant modulus of elasticity.

The mean value of concrete's tensile strength and secant modulus of elasticity are estimated in accordance with EC2 [18]:

$$
\begin{aligned}
f_{\mathrm{ctm}} & =0.30 \sqrt[3]{\left(f_{\mathrm{cm}}-8\right)^{2}}, \\
E_{\mathrm{cm}} & =22\left(\frac{f_{\mathrm{cm}}}{10}\right)^{0.3} .
\end{aligned}
$$

The ratio of ultimate strain of concrete in tension and the strain of FRP reinforcement can be calculated as follows: 


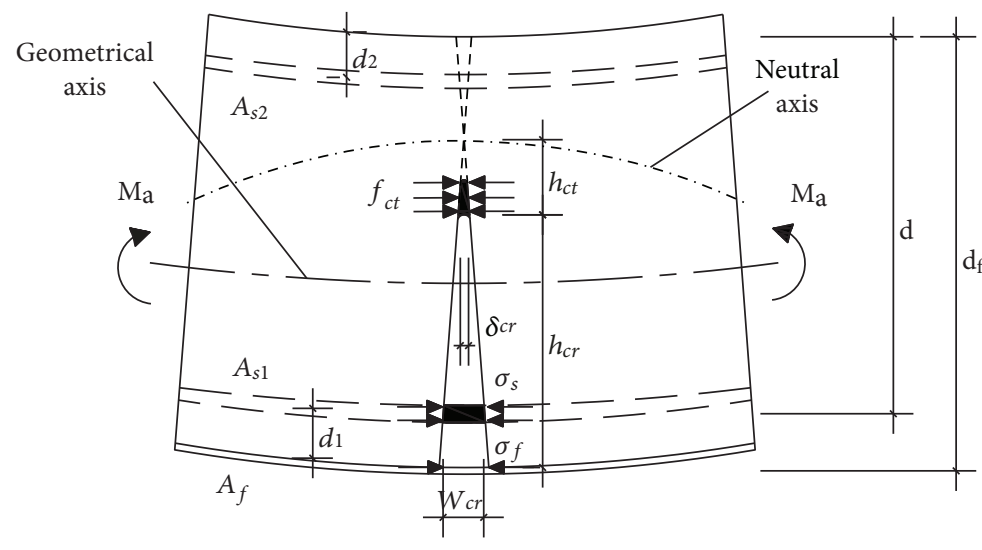

(a)

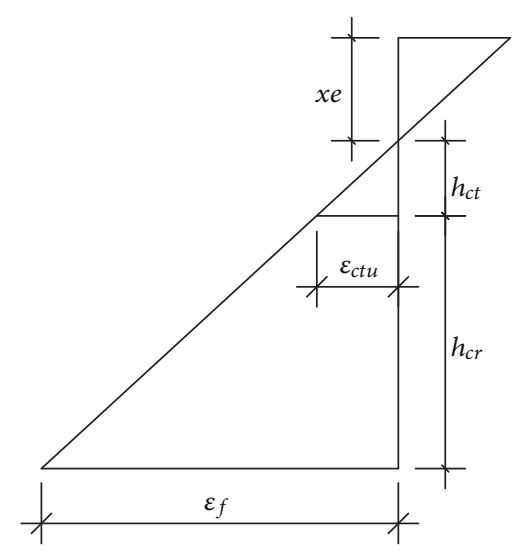

(b)

FIgURE 1: The model for calculation of normal crack propagation: (a) crack model; (b) strain distribution.

$$
\begin{aligned}
\frac{\varepsilon_{\mathrm{ctu}}}{\varepsilon_{f}} & \approx \frac{2 f_{\mathrm{ctm}}\left(\alpha_{\mathrm{s} 1} A_{\mathrm{s} 1}\left(\left(d-x_{e}\right) /\left(d_{f}-x_{e}\right)\right)\left(d-x_{e} / 3\right)+\alpha_{f} A_{f}\left(d_{f}-x_{e} / 3\right)+\alpha_{\mathrm{s} 2} A_{\mathrm{s} 2}\left(\left(x_{e}-d_{2}\right) /\left(d_{f}-x_{e}\right)\right)\left(x_{e} / 3-d_{2}\right)\right)}{M_{a}-A_{f} E_{f}\left(\varepsilon_{p}-\varepsilon_{0}\right)\left(d_{f}-x_{e} / 3\right)}, \\
x_{e} & =\frac{\sqrt{B_{e}^{2}+2\left(b-2 \alpha_{f} A_{f}\left(\left(M_{p}-M_{0}\right) / M_{a} x_{0}\right)\right)\left(\alpha_{\mathrm{s} 2} A_{\mathrm{s} 2} d_{2}+\alpha_{\mathrm{s} 1} A_{\mathrm{s} 1} d+\alpha_{f} A_{f} d_{f}\right)}-B_{e}}{b-2 \alpha_{f} A_{f}\left(\left(M_{p}-M_{0}\right) / M_{a} x_{0}\right)}, \\
B_{e} & =\alpha_{\mathrm{s} 2} A_{\mathrm{s} 2}+\alpha_{\mathrm{s} 1} A_{\mathrm{s} 1}+\alpha_{f} A_{f},
\end{aligned}
$$

where $\alpha_{\mathrm{s} 1}, \alpha_{\mathrm{s} 2}$, and $\alpha_{f}$ are the ratios of elasticity modules of steel reinforcements and FRP reinforcement, respectively; $\varepsilon_{p}$ is the FRP prestressing strain and $\varepsilon_{0}$ is the initial strain; $M_{p}$ and $M_{0}$ are the bending moment caused by the pretensioning force and the initial bending moment, respectively; and $x_{0}$ is the initial depth of the concrete compressive zone.

A wide range of experimental research was conducted by Jokūbaitis et al. [23-28], and the empirical expression of the critical width of a normal crack tip was derived for flexural RC elements:

$$
\delta_{\text {cr. } 0} \approx 0.00012 d_{1} \sqrt[3]{\phi} \mu,
$$

where $d_{1}$ is the distance to the tensile steel reinforcement resultant (see Figure 1), $\phi$ is the diameter of tensile steel reinforcement, and $\mu$ is the parameter, which evaluates the influence of different factors (cross-section, bond between concrete and reinforcement, and reinforcement ratio) on the relation between the crack parameters.

Below is the same expression with some modifications which could be used for FRP-strengthened structures:

$$
\delta_{\mathrm{cr}} \approx 0.00012 d_{1 . \mathrm{eff}} \sqrt[3]{\phi_{\mathrm{eq}}} \mu,
$$

where $\phi_{\mathrm{eq}}$ is the equivalent factor of tensile zone; $\mu$ is the parameter evaluating the influence of the cross-section of the element and bond between concrete and FRP reinforcement (the reinforcement ratio is already taken into account estimating the equivalent factor of the tensile zone):

$$
\mu=\frac{\beta \vartheta(b, h)}{\psi_{f}},
$$

where $\beta=2$ and 1 for long-term and short-term loading, respectively; $\vartheta(b, h)$ is the empirical function of crosssectional parameters; and $\psi_{f}$ is the reduction factor of stiffness in the interface between the RC member and FRP based on the built-up-bar theory $[12,16,17]$ :

$$
\psi_{f}=1-\frac{\operatorname{sh}\left(\lambda \cdot L_{s}\right) \cdot \operatorname{ch}\left(\lambda \cdot\left(L / 2-L_{s}\right)\right)}{\lambda \cdot L_{s} \cdot \operatorname{ch}((\lambda \cdot L) / 2)} .
$$

Factor $\lambda$ evaluates the stiffness of the interface and could be calculated as follows:

$$
\lambda=\sqrt{\xi \cdot \gamma} .
$$

Stiffness of the interface between separate members:

$$
\xi=\frac{u_{f} G_{\text {eff }}}{a},
$$

where $a$ is the distance between the centroids of the RC beam and FRP; $G_{\text {eff }}$ is the effective shear modulus [12]:

$$
G_{\text {eff }}=0.001 \cdot K \cdot E_{\mathrm{cm}} \text {, }
$$




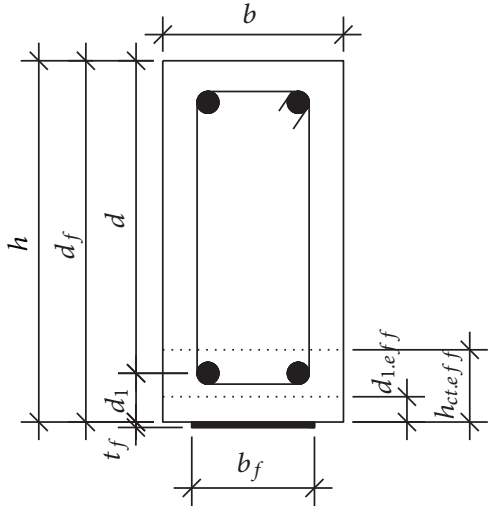

(a)

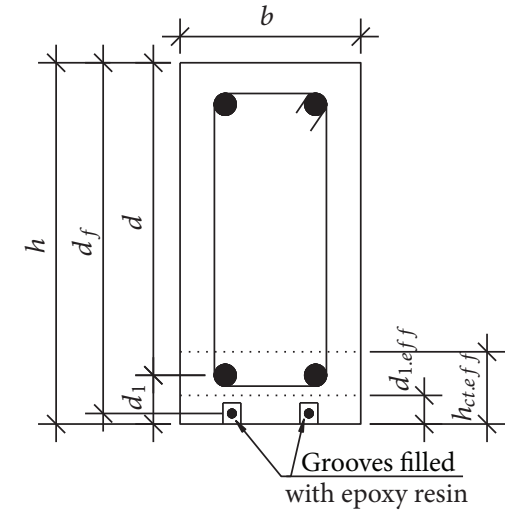

(b)

Figure 2: Effective tension area: (a) EBR; (b) NSM.

where $K$ is the coefficient evaluating the anchorage of FRP. $K=1$ when FRP is not anchored, $K=1.5$ when steel plates are used for the anchorage, and $K=2.0$ when FRP wraps or interlocking grooves are used for the anchorage.

Factor $\gamma$ could be calculated as follows:

$$
\gamma=\frac{1}{E_{\mathrm{cm}} A_{\text {c.eff }}}+\frac{1}{E_{f} A_{f}}+\frac{a^{2}}{E_{\mathrm{cm}} I_{\text {c.eff }}},
$$

where $A_{\text {c.eff }}$ and $I_{\text {c.eff }}$ are the area and the moment of inertia of a cracked concrete cross-section, respectively. For rectangular cross-sections

$$
\begin{gathered}
A_{\text {c.eff }}=b x_{e}, \\
I_{\text {c.eff }}=\frac{b x_{e}^{3}}{3} .
\end{gathered}
$$

The distance to tensile steel and FRP-reinforcement resultant (in mm) (see Figure 2) is as follows:

$$
\begin{aligned}
d_{1 . \mathrm{eff}} & =d_{1}-\frac{A_{f} \sigma_{f}\left(d_{f}-d\right)}{A_{f} \sigma_{f}+A_{\mathrm{s} 1} \sigma_{\mathrm{s} 1}} \\
& =d_{1}-\frac{A_{f} E_{f}\left(d_{f}-d\right)}{A_{f} E_{f}+A_{\mathrm{s} 1} E_{\mathrm{s} 1}\left(\left(d-x_{e}\right) /\left(d_{f}-x_{e}\right)\right)} .
\end{aligned}
$$

In EC2, the effective reinforcement ratio of tensile zone of concrete is expressed as follows:

$$
\rho_{\text {t.eff }}=\frac{A_{\text {s1 }}+\xi_{1} A_{p}}{A_{\text {ct.eff }}}
$$

where $A_{p}$ is the area of pre- or posttensioned tendons within $A_{\text {ct.eff }}$ and $\xi_{1}$ is the adjusted ratio of bond strength taking into account the different diameters of prestressing and reinforcing steel.

As proposed in [21] for FRP-strengthened RC structures, $A_{p}=A_{f}$ and $\xi_{1}=E_{f} / E_{\mathrm{s} 1}$; then the effective reinforcement ratio of the tensile zone of concrete will be as follows:

$$
\rho_{\text {t.eff }}=\frac{A_{\mathrm{s} 1}+A_{f} E_{f} / E_{\mathrm{s} 1}}{A_{\text {ct.eff }}}
$$

where $A_{\text {ct.eff }}$ is the effective area of concrete in tension:

$$
A_{\text {ct.eff }}=b h_{\text {ct.eff }}=\min \left\{\begin{array}{l}
2.5 b d_{1 . e f f}, \\
\frac{b\left(h-x_{e}\right)}{3}, \\
\frac{h}{2} .
\end{array}\right.
$$

The equivalent factor of the tensile zone, taking into account both steel and FRP reinforcements, can be derived from (2) and (4):

$$
\phi_{\text {eq }}=\frac{8 \rho_{\text {t.eff }} A_{\text {ct.eff }} f_{\mathrm{ctm}} \xi_{b} E_{f} A_{f}}{\tau_{\mathrm{fm}} u_{f}\left(E_{s} A_{s}+\xi_{b} E_{f} A_{f}\right) k_{1} k_{2}},
$$

where the bond perimeter of FRP reinforcement $u_{f}$ is determined from Figure 3.

Subsequently, the crack width is derived from (7) and (10):

$$
w_{\mathrm{cr} . \mathrm{f}}=\frac{\delta_{\mathrm{cr}}\left(M_{a}-A_{f} E_{f}\left(\varepsilon_{p}-\varepsilon_{0}\right)\left(d_{f}-x_{e} / 3\right)\right)}{2 f_{\mathrm{ctm}}\left(\alpha_{\mathrm{s} 1} A_{\mathrm{s} 1}\left(\left(d-x_{e}\right) /\left(d_{f}-x_{e}\right)\right)\left(d-x_{e} / 3\right)+\alpha_{f} A_{f}\left(d_{f}-x_{e} / 3\right)+\alpha_{\mathrm{s} 2} A_{\mathrm{s} 2}\left(\left(x_{e}-d_{2}\right) /\left(d_{f}-x_{e}\right)\right)\left(x_{e} / 3-d_{2}\right)\right)},
$$




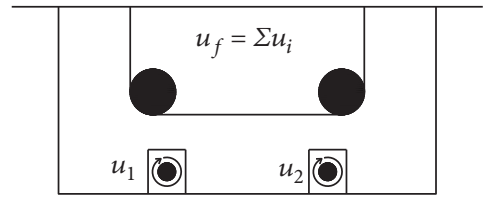

(a)

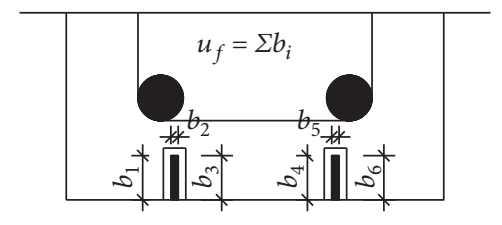

(b)

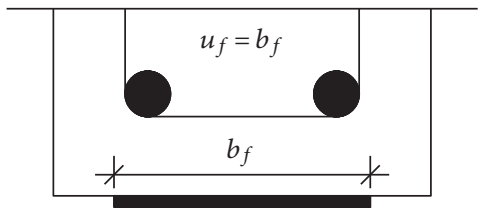

(c)

FIGURE 3: Bond perimeter of FRP reinforcement: (a) FRP rods; (b) FRP strips; (c) EBR.

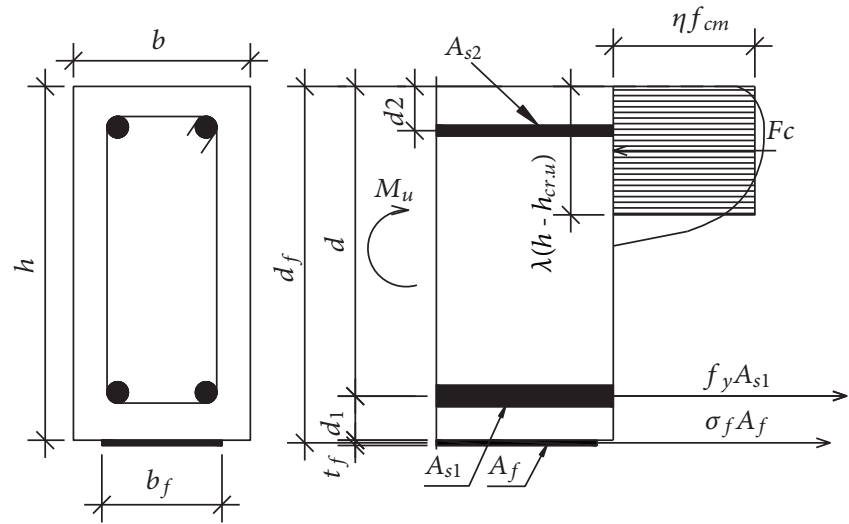

(a)

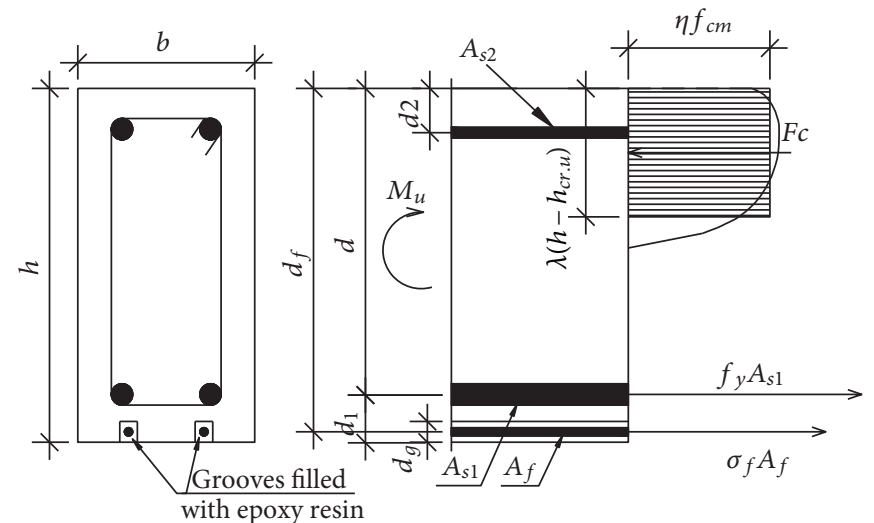

(b)

FIGURE 4: State of stress in RC beam strengthened with (a) EB FRP reinforcement and (b) NSM FRP reinforcement.

where $d$ and $d_{f}$ are the depths of inner and external reinforcements, respectively. If the structure was already cracked at the strengthening moment, the initial crack width should be added to calculation:

$w_{\text {cr }}=w_{\text {cr.f }}+w_{\text {cr. } 0}$,

$w_{\mathrm{cr} .0}=\frac{\delta_{\mathrm{cr} .0} M_{0}}{2 f_{\mathrm{ctm}}\left(\alpha_{\mathrm{s} 1} A_{\mathrm{s} 1}\left(d-x_{0} / 3\right)+\alpha_{\mathrm{s} 2} A_{\mathrm{s} 2}\left(\left(x_{0}-d_{2}\right) /\left(d-x_{0}\right)\right)\left(x_{0} / 3-d_{2}\right)\right)}$.

2.2.2. Relation between Crack Depth and Load-Carrying Capacity. The same relation in (7) relates the crack depth with the acting bending moment and the depth of the concrete tensile zone, whose relation with crack parameters can be expressed as follows:

$$
h_{\mathrm{ct}} \approx \frac{\delta_{\mathrm{cr}}}{w_{\mathrm{cr}}} h_{\mathrm{cr}} .
$$

Furthermore, there will always be a retained condition:

$$
h=h_{\mathrm{cr}}+\frac{\delta_{\mathrm{cr}}}{w_{\mathrm{cr}}} h_{\mathrm{cr}}+x_{e} .
$$

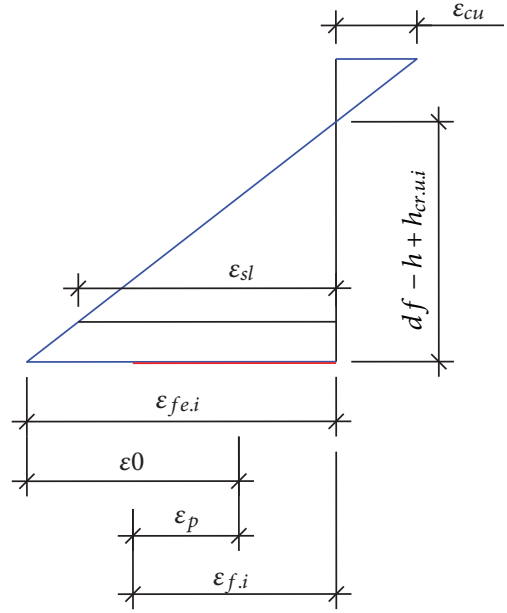

FIGURE 5: Limit state of strain in the flexural member.

Therefore, the crack depth can be expressed as follows:

$$
h_{\mathrm{cr}}=\frac{h-x_{e}}{1+\delta_{\mathrm{cr}} / w_{\mathrm{cr}}}=\frac{h-x_{e}}{1+\varepsilon_{\mathrm{ctu}} / \varepsilon_{f}} \text {. }
$$

When the load of the RC element strengthened with FRP is close to its ultimate value, the strain in tensile steel 
reinforcement, in most cases, shall exceed the yield strength and large plastic deformations will occur in the element $\left(\delta_{\mathrm{cr}} / w_{\mathrm{cr}} \rightarrow 0, \varepsilon_{\mathrm{ctu}} / \varepsilon_{f} \rightarrow 0\right.$, and $\left.h_{\mathrm{ct}} \rightarrow 0\right)$. Therefore, the tensile zone of concrete above the crack can be disregarded, and the ultimate crack depth of the element could be evaluated according to Figure 4, by using the equivalent rectangular concrete compressive stress diagram.

Although FRP stress is unknown, the equilibrium condition between the ultimate crack depth and the FRP stress can be reached iteratively. This way, the ultimate crack depth could be evaluated by the following:

$$
h_{\text {cr.u.i }} \approx h-\frac{A_{\mathrm{s} 1} f_{y}+A_{f} \sigma_{\mathrm{f} . \mathrm{i}}}{\eta \lambda f_{\mathrm{cm}} b},
$$

where $f_{y}$ and $f_{\mathrm{cm}}$ are the yield strength of tensile steel reinforcement and the mean value of concrete compressive strength, respectively, and $\eta$ and $\lambda$ are the reduction factors of concrete compressive strength and compressive zone height, respectively (in accordance with EC2 [18]: $\eta=1.0$, $\lambda=0.8$ for concrete strength $f_{\mathrm{ck}}<50 \mathrm{MPa}$ ). The FRP stress of $i$ th iteration can be found, assuming the linear elastic stress-strain relationship, but it must be lower than the design strength:

$$
\sigma_{\mathrm{f} . \mathrm{i}}=E_{f} \varepsilon_{\mathrm{f} . \mathrm{i}} \leq f_{f}
$$

where $\varepsilon_{\text {f.i }}$ is a FRP strain, which could be determined from Figure 5.

In accordance with EC2 [18], the ultimate strain of the compressive concrete $\varepsilon_{\text {cu }}$ could be taken as $3.5 \%$, when $f_{\mathrm{ck}}<50 \mathrm{MPa}$. Iterations are repeated until equilibrium condition is achieved:

$$
\sigma_{\mathrm{f} . \mathrm{n}} \approx \sigma_{\mathrm{f} . \mathrm{n}-1} .
$$

Afterwards, the compressive reinforcement stress is calculated and the ultimate crack depth is revised, evaluating the impact of compressive reinforcement and reduced stiffness in the interface between the RC member and the FRP reinforcement.

$$
\begin{aligned}
\sigma_{\mathrm{s} 2} & =E_{\mathrm{s} 2} \psi_{f} \varepsilon_{\mathrm{fe}} \frac{h-h_{\mathrm{cr} . \mathrm{u}}-d_{2}}{d_{f}-h+h_{\mathrm{cr} . \mathrm{u}}} \leq f_{\mathrm{y} . \mathrm{s} 2}, \\
h_{\mathrm{cr} . \mathrm{u}} & =h-\frac{\left(A_{\mathrm{s} 1} f_{y}+A_{f} \psi_{f} \sigma_{f}-A_{\mathrm{s} 2} \sigma_{\mathrm{s} 2}\right)^{2}}{\eta \lambda f_{\mathrm{cm}} b\left(A_{\mathrm{s} 1} f_{y}+A_{f} \psi_{f} \sigma_{f}\right)},
\end{aligned}
$$

where the reduction factor $\psi_{f}$ is taken from (16), (17), (18), (19), (20), (21), and (22), only that $A_{\text {c.eff }}=b\left(h-h_{\text {cr.u }}\right)$ and $I_{\text {c.eff }}=b\left(h-h_{\text {cr.u }}\right)^{3} / 3$.

Real reduction coefficients of a concrete compressive zone stress diagram can be determined using the modified technique proposed by Dulinskas et al. [29] (see Figure 6).

The areas of separate parts and the whole curvilinear concrete's compressive zone diagram [30]:

$$
\begin{aligned}
A_{\mathrm{asc}} & =\frac{1}{2} 2 x_{\mathrm{asc}} \frac{2}{3} f_{\mathrm{cm}}=\frac{2}{3} f_{\mathrm{cm}}\left(h-h_{\mathrm{cr} . \mathrm{u}}\right) \frac{\varepsilon_{\mathrm{c} 1}}{\varepsilon_{\mathrm{c} 2}}, \\
A_{\mathrm{desc} 2} & =f_{\mathrm{cm}} x_{\mathrm{desc}}=f_{\mathrm{cm}}\left(1-\frac{\varepsilon_{\mathrm{c} 1}}{\varepsilon_{\mathrm{c} 2}}\right)\left(h-h_{\mathrm{cr} . \mathrm{u}}\right), \\
A_{\mathrm{desc} 3} & =A_{\mathrm{sum}}-A_{\mathrm{asc}}-A_{\mathrm{des} 2}, \\
A_{\mathrm{sum}} & =\frac{A_{\mathrm{s} 1} f_{y}+A_{f} \psi_{f} \sigma_{f}-A_{\mathrm{s} 2} \sigma_{\mathrm{s} 2}}{b},
\end{aligned}
$$

where the concrete strain at peak stress [18] is $\varepsilon_{\mathrm{cl}}=0.7 f_{\mathrm{cm}}^{0.31}$ $\leq 2.8$ and the concrete ultimate strain $\varepsilon_{\mathrm{c} 2}=\varepsilon_{\mathrm{fe}}\left(h-h_{\mathrm{cr} . \mathrm{u}}\right) /$ $\left(d_{f}-\left(h-h_{\text {cr.u }}\right)\right)$.

When $A_{\text {desc3 }}<0$, the descending part of concrete's compressive zone diagram exists and it is possible to calculate its parameters.

$$
\begin{aligned}
& \lambda=\frac{2 x_{c}}{h-h_{\text {cr.u }}} \leq 1.0, \\
& \eta=\frac{A_{\text {sum }}}{f_{c m} \lambda\left(h-h_{\text {cr.u }}\right)} \leq 1,0 ;
\end{aligned}
$$

where $x_{c}$ is a coordinate of centroid of curvilinear concrete's compressive zone stress diagram:

$$
x_{c}=\frac{\sum A_{i} x_{\mathrm{ci}}}{A_{\mathrm{sum}}} .
$$

If $\varepsilon_{\mathrm{c} 2}<\varepsilon_{\mathrm{c} 1}$, there will not be any descending part and the area of the ascending part would be equal to the area of the whole curvilinear concrete compressive zone diagram. The strength of compressive concrete will not be reached (see Figure 7), and maximum stress in the most compressed fibre can be determined by stress-strain relation for nonlinear structural analysis proposed in EC2 [18]:

$$
\begin{aligned}
\sigma_{c} & =f_{\mathrm{cm}} \frac{k \varepsilon_{\mathrm{c} 2} / \varepsilon_{\mathrm{c} 1}-\left(\varepsilon_{\mathrm{c} 2} / \varepsilon_{\mathrm{c} 1}\right)^{2}}{1+(k-2)\left(\varepsilon_{\mathrm{c} 2} / \varepsilon_{\mathrm{c} 1}\right)}, \\
k & =\frac{1.05 E_{c}\left|\varepsilon_{\mathrm{c} 1}\right|}{f_{\mathrm{cm}}} .
\end{aligned}
$$

Next, the ascending part of the concrete stress diagram is divided into the simpler figures, and the parameters of equivalent stress diagram are calculated by (43) and (44).

Subsequently, the flexural strength of the strengthened member can be expressed as

$$
\begin{aligned}
M_{\mathrm{u} . \mathrm{calc}}= & \eta f_{\mathrm{cm}} b \lambda\left(h-h_{\mathrm{cr} . \mathrm{u}}\right)\left(h-\frac{\lambda\left(h-h_{\mathrm{cr} . \mathrm{u}}\right)}{2}\right) \\
& +A_{\mathrm{s} 2} \sigma_{\mathrm{s} 2}\left(h-d_{2}\right) .
\end{aligned}
$$

A simplified methodology proposed by Slaitas et al. [31] could be used for nonstrengthened RC structures, using a triangular concrete compressive zone stress diagram. 


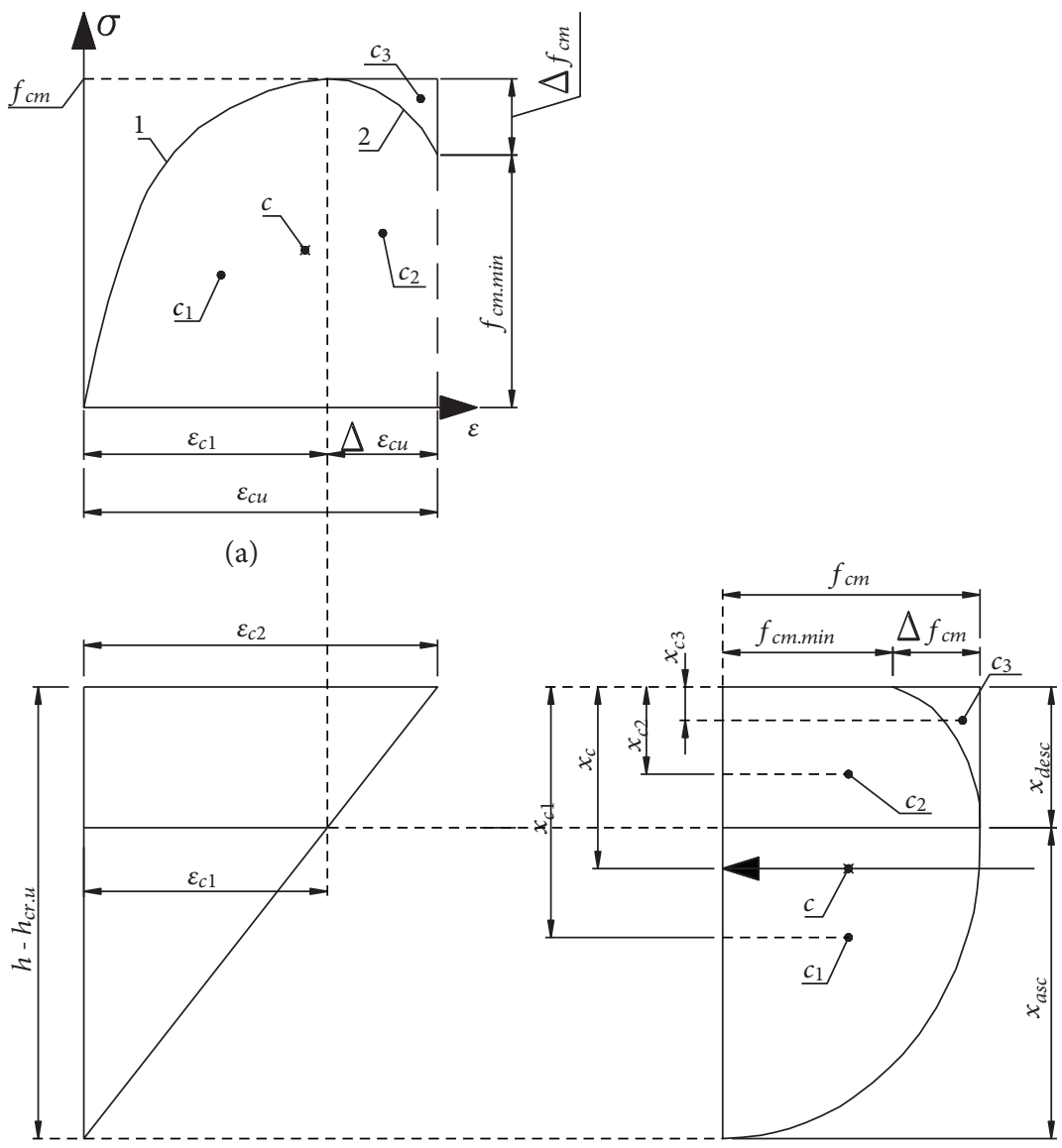

(b)

(c)

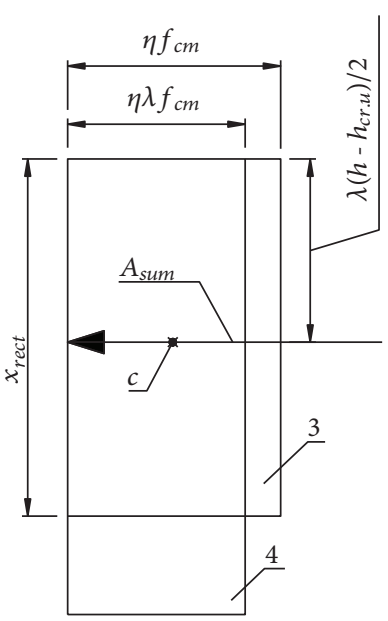

(d)

FIGURE 6: Stress distribution diagrams for concrete in compression: (a) curvilinear: 1—ascending part, 2-descending part; (b) strains in the cross-section; (c) curvilinear concrete's compressive zone stress diagram and centroids of its parts: $c$-whole stress diagram, $c_{1}$-ascending part, $c_{2}$-constant (rectangular) part, $c_{3}$-separated part from rectangular by curved descending line, and $x_{c}, x_{c 1}$, $x_{c 2}$, and $x_{c 3}-$ the coordinates of centroids of stress diagram parts; and (d) rectangular stress diagrams: 3-equivalent and 4-inequivalent [30].

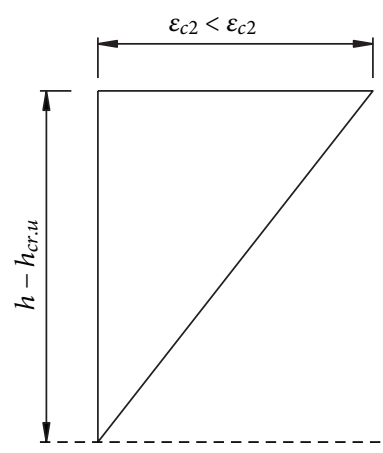

(a)

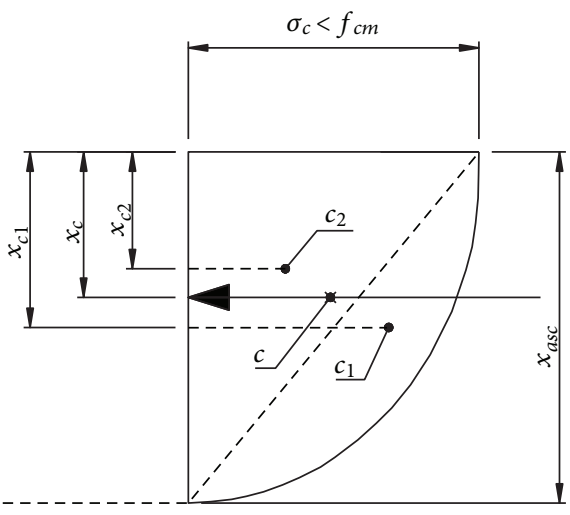

(b)

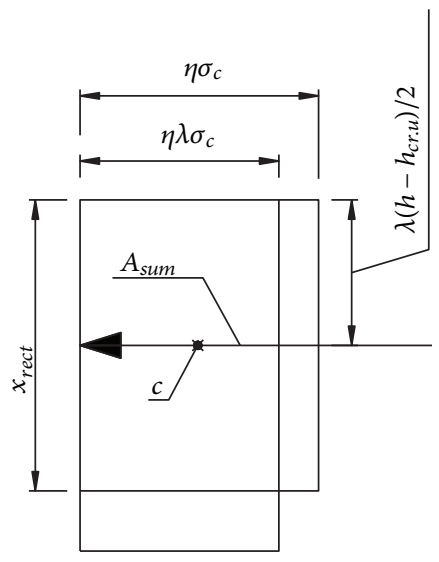

(c)

FIGURE 7: Stress distribution diagrams for concrete in compression, when mean value of concrete compressive strength is not reached: (a) strains in cross-section; (b) curvilinear concrete compressive zone stress diagram; (c) rectangular stress diagram.

The analytical model proposed above could be used for more reliable prediction of concrete crack parameters and flexural strength for FRP-strengthened RC structures.
2.3. Analysed Beams. Four-point bending tests were carried out on seven full-scale beams (see Figure 8). The experimental beams varied by length, material properties, 


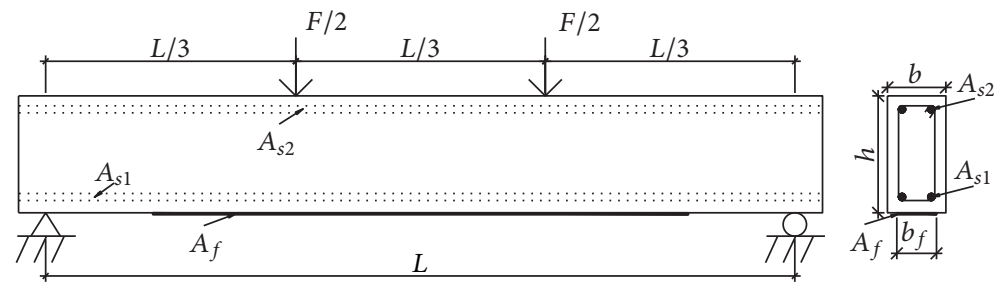

FIgURE 8: Loading scheme of tested beams.

TABle 1: Properties of specimens and materials.

\begin{tabular}{|c|c|c|c|c|c|c|c|c|c|c|c|}
\hline Beam ID & $b(\mathrm{~m})$ & $h(\mathrm{~m})$ & $L(\mathrm{~m})$ & $A_{\mathrm{s} 1}\left(\mathrm{~mm}^{2}\right)$ & $f_{y}(\mathrm{MPa})$ & $A_{f}\left(\mathrm{~mm}^{2}\right)$ & $f_{f}(\mathrm{MPa})$ & $A_{\mathrm{s} 2}\left(\mathrm{~mm}^{2}\right)$ & $M_{0}(\mathrm{kNm})$ & $f_{\mathrm{cm}}(\mathrm{MPa})$ & Anchored \\
\hline$\overline{\mathrm{CB}}$ & 0.15 & 0.3 & 2.7 & 308 & 569 & - & - & 226 & 0 & 25.40 & - \\
\hline B1-0 & 0.15 & 0.3 & 2.7 & 308 & 569 & 144 & 2334 & 226 & 0 & 25.40 & Yes \\
\hline $\mathrm{B} 2-\mathrm{P}^{*}$ & 0.15 & 0.3 & 2.7 & 308 & 569 & 144 & 2334 & 226 & 0 & 25.40 & Yes \\
\hline B3-0 & 0.1 & 0.2 & 1.2 & 226 & 318 & 16.7 & 4800 & 100 & 0 & 28.70 & No \\
\hline B4-0 & 0.1 & 0.2 & 1.2 & 226 & 318 & 16.7 & 4800 & 100 & 0 & 28.70 & No \\
\hline B5-7 & 0.1 & 0.2 & 1.2 & 226 & 318 & 16.7 & 4800 & 100 & 7 & 28.70 & No \\
\hline B6-7 & 0.1 & 0.2 & 1.2 & 226 & 318 & 16.7 & 4800 & 100 & 7 & 28.70 & No \\
\hline
\end{tabular}

${ }^{*}$ FRP was prestressed, $\sigma_{p}=120 \mathrm{MPa}$.

TABle 2: Properties of additional beams for serviceability stage [21].

\begin{tabular}{|c|c|c|c|c|c|c|c|c|c|}
\hline Beam ID & $b \times h(\mathrm{~mm})$ & $L(\mathrm{~mm})$ & $A_{\mathrm{s} 1}\left(\mathrm{~mm}^{2}\right)$ & $f_{y}(\mathrm{MPa})$ & $A_{f}\left(\mathrm{~mm}^{2}\right)$ & $f_{f}(\mathrm{MPa})$ & $A_{\mathrm{s} 2}\left(\mathrm{~mm}^{2}\right)$ & $M_{s}^{*}(\mathrm{kNm})$ & Anchored \\
\hline $1-\mathrm{A} 2$ & $180 \times 100$ & 2000 & 157 & 456 & 16.70 & 3450 & 100 & 10.63 & No \\
\hline $1-\mathrm{A} 3$ & $180 \times 100$ & 2000 & 157 & 456 & 33.40 & 3450 & 100 & 11.90 & No \\
\hline $1-\mathrm{A} 4$ & $180 \times 100$ & 2000 & 157 & 456 & 33.40 & 3450 & 100 & 11.05 & No \\
\hline $1-A 5$ & $180 \times 100$ & 2000 & 157 & 456 & 16.70 & 3450 & 100 & 12.33 & No \\
\hline $1-A 7$ & $180 \times 100$ & 2000 & 157 & 456 & 16.70 & 3450 & 100 & 12.75 & No \\
\hline $1-\mathrm{A} 8$ & $180 \times 100$ & 2000 & 100 & 513 & 16.70 & 3450 & 157 & 7.86 & No \\
\hline $1-\mathrm{B} 2$ & $180 \times 100$ & 1800 & 226 & 432 & 16.70 & 3450 & 100 & 12.75 & No \\
\hline $1-\mathrm{B} 3$ & $180 \times 100$ & 1800 & 226 & 432 & 33.40 & 3450 & 100 & 12.00 & No \\
\hline $1-B 4$ & $180 \times 100$ & 1800 & 226 & 432 & 33.40 & 3450 & 100 & 10.50 & No \\
\hline $1-B 5$ & $180 \times 100$ & 1800 & 226 & 432 & 16.70 & 3450 & 100 & 12.75 & No \\
\hline $1-B 7$ & $180 \times 100$ & 1800 & 226 & 432 & 16.70 & 3450 & 100 & 13.13 & No \\
\hline $2-\mathrm{A} 2$ & $150 \times 100$ & 1800 & 100 & 530 & 18.15 & 3450 & 100 & 4.61 & No \\
\hline $2-\mathrm{A} 3$ & $150 \times 100$ & 1800 & 100 & 530 & 18.15 & 3450 & 100 & 4.80 & No \\
\hline $2-\mathrm{A} 4$ & $150 \times 100$ & 1800 & 100 & 530 & 16.50 & 3450 & 100 & 4.91 & No \\
\hline $2-B 2$ & $150 \times 100$ & 1800 & 157 & 570 & 18.15 & 3450 & 157 & 6.45 & No \\
\hline $2-\mathrm{B} 3$ & $150 \times 100$ & 1800 & 157 & 570 & 18.15 & 3450 & 157 & 6.45 & No \\
\hline $2-B 4$ & $150 \times 100$ & 1800 & 157 & 570 & 33.00 & 3450 & 157 & 6.19 & No \\
\hline $2-\mathrm{C} 3$ & $100 \times 150$ & 1800 & 100 & 530 & 13.20 & 3450 & 100 & 4.46 & No \\
\hline $2-\mathrm{C} 4$ & $100 \times 150$ & 1800 & 100 & 530 & 13.20 & 3450 & 100 & 4.01 & No \\
\hline 2-D3 & $100 \times 150$ & 1400 & 157 & 570 & 13.20 & 3450 & 157 & 7.34 & No \\
\hline $2-\mathrm{E} 3$ & $100 \times 150$ & 1800 & 314 & 570 & 33.00 & 3450 & 157 & 10.01 & No \\
\hline
\end{tabular}

${ }^{*}$ Crack width checking moment.

reinforcement ratio, and strengthening. Beam $\mathrm{CB}$ served as a control beam. Beams B1-0 and B2-P were strengthened, and the CFRP layer was additionally anchored with steel clumps. Beams B5-7 and B6-7 were strengthened under an external load action. Beams B3-0 and B4-0 were strengthened without an external load action. The CFRP layer of beams B3-0, B4-0, B5-7, and B6-7 was unanchored. The properties of tested beams are listed in Table 1.

Additionally, an extended database of 27 beams total was used for comparison of numerical and experimental 
TABle 3: Properties of additional beams for load-carrying capacity.

\begin{tabular}{|c|c|c|c|c|c|c|c|}
\hline Ref. & $A_{\mathrm{s} 1} / b d(\%)$ & $f_{y}(\mathrm{MPa})$ & $A_{f} / b d_{f}(\%)$ & $f_{f}(\mathrm{MPa})$ & $E_{f}(\mathrm{GPa})$ & $\sigma_{p}(\mathrm{MPa})$ & EBR/NSM \\
\hline [32] & 0.85 & 400 & 0.11 & 3100 & 165 & 1000 & EBR \\
\hline$[32]$ & 0.85 & 400 & $0.13 \div 0.14$ & 2068 & 131 & $0 \div 1000$ & NSM \\
\hline$[33]$ & 0.40 & 426 & $0.04 \div 0.12$ & $2453 \div 3479$ & $165 \div 230$ & 0 & EBR \\
\hline$[33]$ & 0.40 & 426 & $0.04 \div 0.11$ & $1878 \div 2453$ & $121 \div 165$ & 0 & NSM \\
\hline$[34]$ & 0.45 & 436 & $0.04 \div 0.22$ & $1500 \div 2483$ & $100 \div 167$ & 0 & NSM \\
\hline$[35]$ & $0.29 \div 1.19$ & $466 \div 501$ & 0.08 & 2850 & 165 & $0 \div 1323$ & EBR \\
\hline$[36]$ & $0.50 \div 0.75$ & $525 \div 531$ & 0.11 & 3263 & 251 & 0 & EBR \\
\hline [37] & 0.58 & 545 & $0.12 \div 0.26$ & $1350 \div 2350$ & $64 \div 170$ & 0 & NSM \\
\hline$[38]$ & 0.58 & 540 & $0.13 \div 0.26$ & $1350 \div 2500$ & $64 \div 170$ & 0 & NSM \\
\hline [39] & 0.77 & 475 & 0.08 & 2167 & 130 & $0 \div 1241$ & NSM \\
\hline [40] & $0.54 \div 0.94$ & 730 & $0.16 \div 0.24$ & 2740 & 159 & 0 & NSM \\
\hline [41] & 0.39 & 585 & 0.06 & 1922 & 164 & $0 \div 823$ & NSM \\
\hline
\end{tabular}

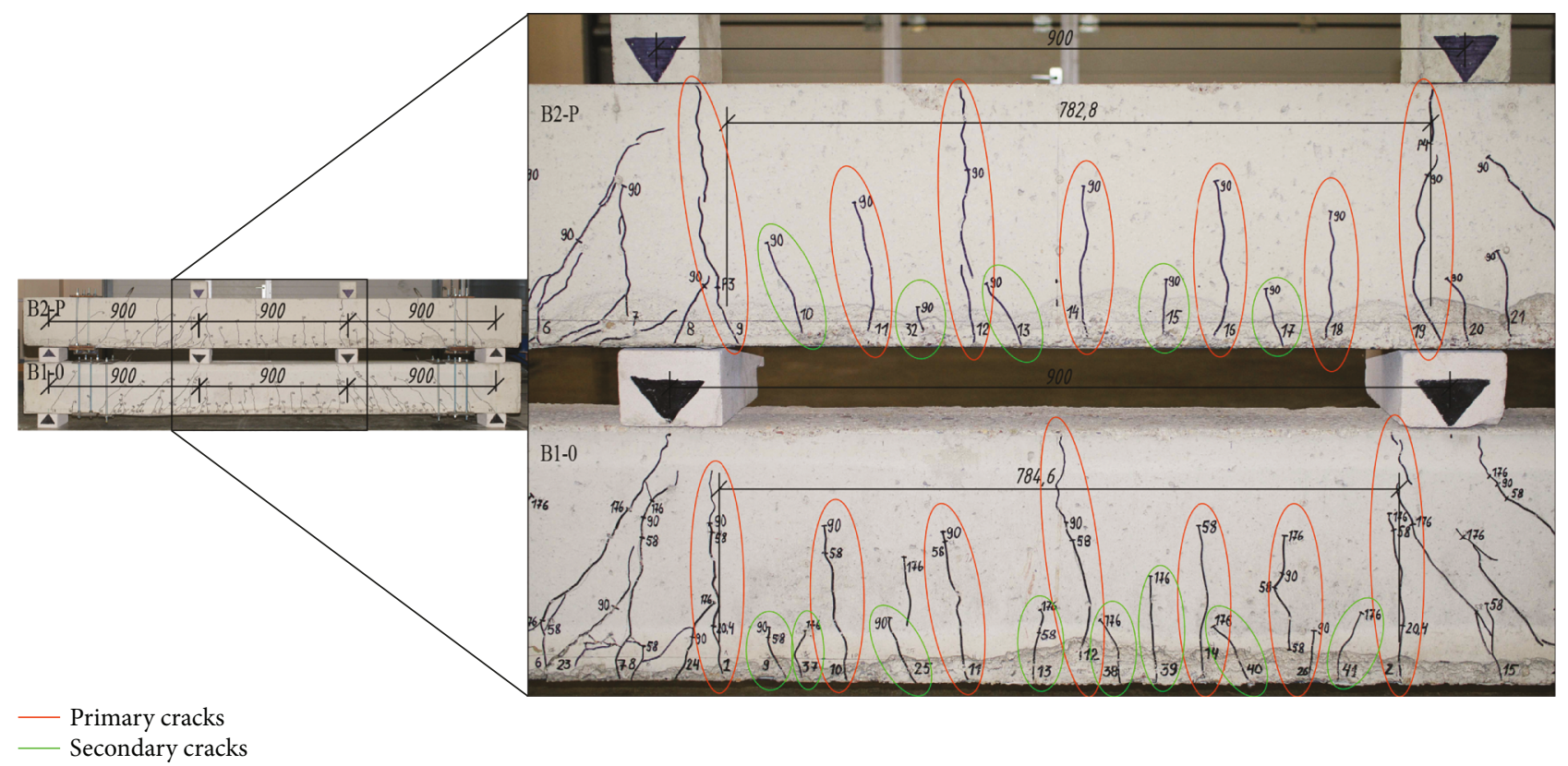

Figure 9: Experimental crack pattern of beams B1-0 and B2-P.

results. Additional 21 beams were taken from a research conducted in [21]. The properties of extra beams are listed in Table 2.

A number of additional RC beams, strengthened with carbon fibre-reinforced polymer (CFRP) and glass fibrereinforced polymer (GFRP) sheets, plates, strips, and rods, tested by different researchers, were analysed in a comparison of numerical and experimental results of load-carrying capacity (sample size: 98 beams). The properties of extra 71 beams are listed in Table 3.

\section{Results and Discussion}

3.1. Crack Pattern. The crack pattern of the higher beams (B1-0 and B2-P) is presented in Figure 9. It can be seen in both beams that the spacing of primary cracks was similar $\left(s_{\text {r.m.P.B1-0 }} \approx s_{\text {r.m.P.B2-P }} \approx 130 \mathrm{~mm}\right)$, but the spacing of secondary cracks was denser in beam B1-0, although the crack widths were smaller in the prestressed beam (B2-P), taking into account secondary cracks: $s_{\text {r.m.P-S.B1-0 }} \approx 56 \mathrm{~mm}$ and $s_{\text {r.m.P-S.B2-P }} \approx 71 \mathrm{~mm}$, and crack widths under service load: $w_{\text {cr.B1- } 0} \approx 0.200 \mathrm{~mm}$ and $w_{\text {cr.B2-P }} \approx 0.075 \mathrm{~mm}$. The maximum crack width was reduced by 2.67 times by prestressing the external reinforcement. This was evaluated in the proposed method (calculated crack width of B1-0 was 2.55 times bigger than B2-P).

The crack pattern of smaller beams (B3-0, B4-0, B5-7, and B6-7) is presented in Figure 10.

In beams without initial strain, the crack distribution was denser, because from the start the beams had higher 


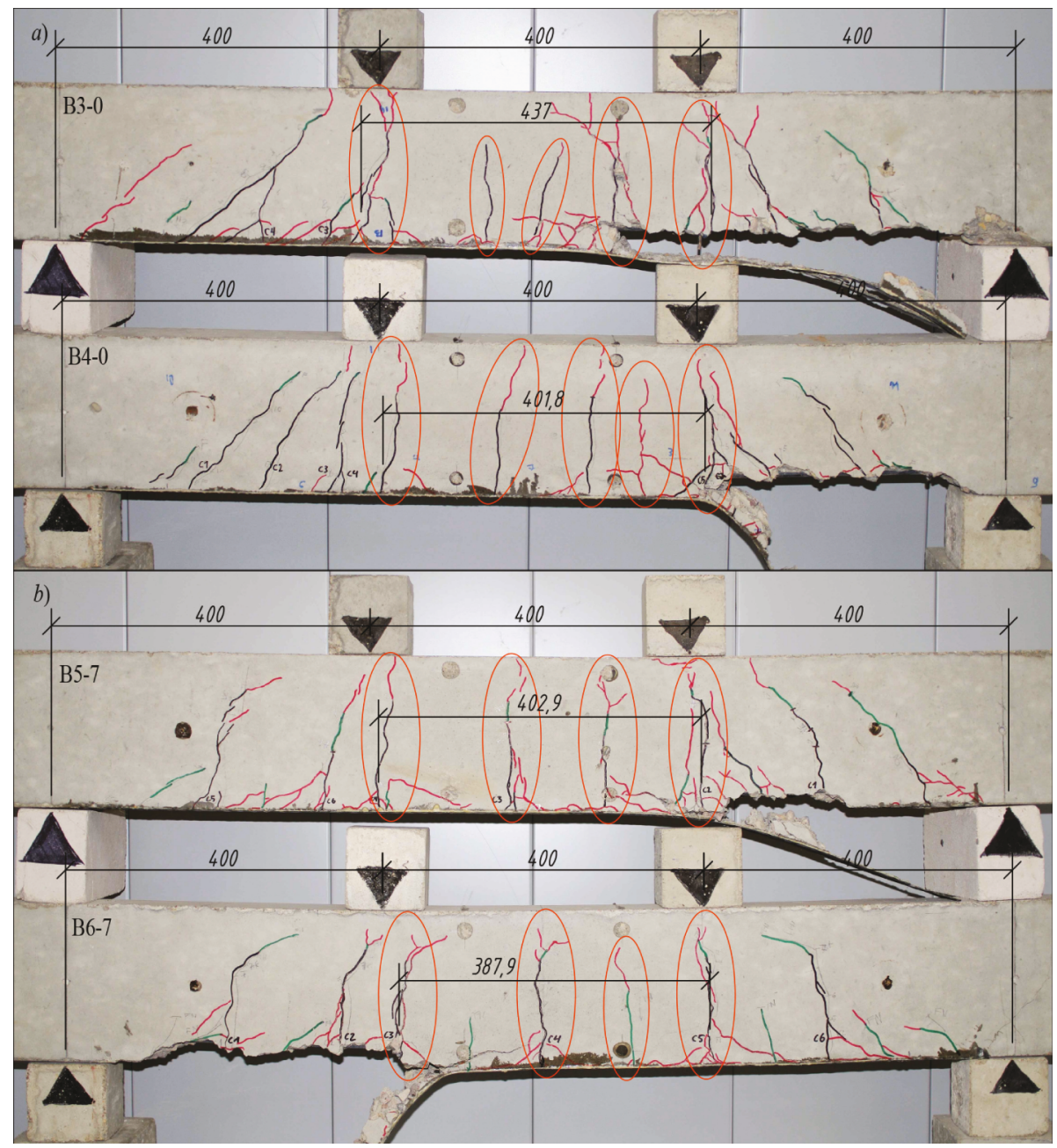

Figure 10: Experimental crack pattern of beams B3-0, B4-0, B5-7, and B6-7.

reinforcement ratios. Until the strengthening moment, the beams B5-7 and B6-7 were acting as ordinary RC beams and the primary cracks had already developed; after strengthening, the crack development was slower, but the spacing remained the same as earlier; that is, the distribution and propagation of cracks are different if the stiffness of beams at the moment of strengthening is different. As a result, crack widths of the beams strengthened under external load action (B5-7, B6-7) were 2 times higher than those strengthened without it (B3-0, B4-0). This validates the evaluation of the initial crack width in (29).

It should be mentioned that in smaller beams, mainly primary cracks were developing and the absence of anchorage has led to the horizontal cracks in the contact zone of concrete and FRP, which appeared when the external load has reached about $80 \%$ of the load-carrying capacity. The failure result of these beams was concrete cover separation.

3.2. Function of Cross-Sectional Parameters. The function of cross-sectional parameters $\vartheta(b, h)$ in (15) could be expressed as a polynomial of the ratio of width and height for a rectangular cross-section (as it has only these 2 parameters):

$$
\vartheta(b, h)=C_{1}\left(\frac{b}{h}\right)^{2}+C_{2}\left(\frac{b}{h}\right)+C_{3},
$$

where $C_{1}, C_{2}$, and $C_{3}$ are constant values, which could be determined empirically from Figure 11.

The constants $C_{1}, C_{2}$, and $C_{3}$ in (49) could be determined from Figure 11, and the values of the function $\vartheta(b, h)$ could be calculated by the following expression (coefficient of correlation 0.89):

$$
\vartheta(b, h)=-0.53\left(\frac{b}{h}\right)^{2}+0.38\left(\frac{b}{h}\right)+1.6 .
$$

3.3. Crack Width. The comparison of experimental and numerical results of the crack widths is presented in Figure 12 and Table 4 . The statistical parameters are shown in Table 4: 


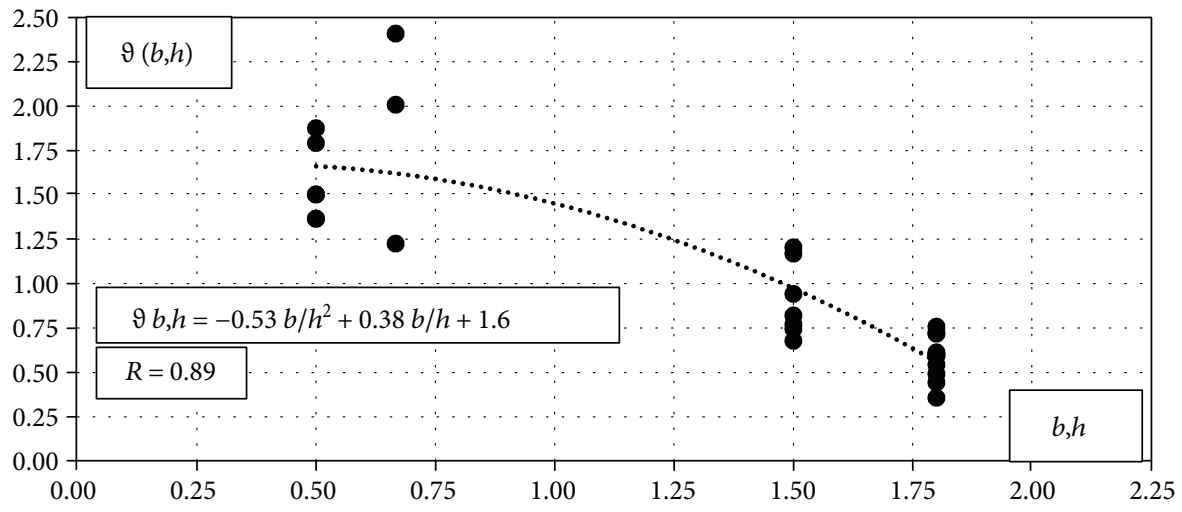

FIGURE 11: The function of cross-sectional parameters $\vartheta(b, h)$.

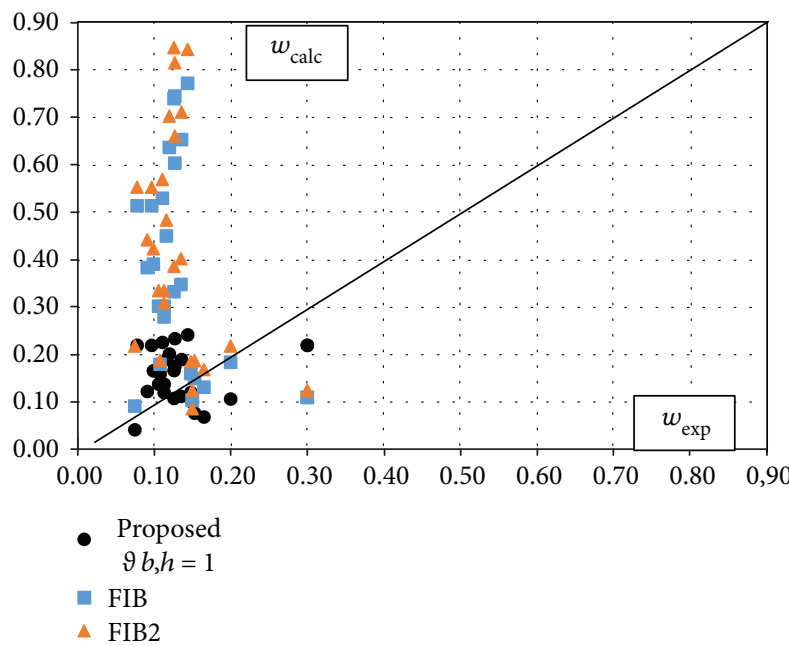

(a)

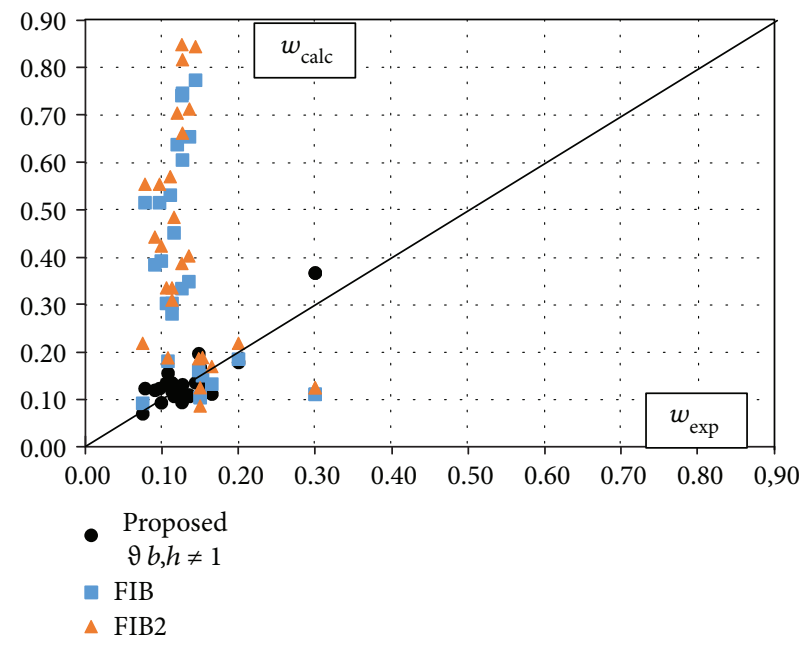

(b)

Figure 12: Comparison of the crack width estimation results with experimental ones at service load: (a) $\vartheta(b, h)=1 ;(b) \vartheta(b, h)$ from $(50)$.

$$
\begin{aligned}
x_{i} & =\frac{w_{\text {exp } . \mathrm{i}}}{w_{\text {calc. } \mathrm{i}}} \\
\bar{x} & =\frac{1}{n} \sum_{i=1}^{n} x_{i}, \\
s & =\sqrt{\frac{1}{n-1} \sum_{i=1}^{n}\left(x_{i}-\bar{x}\right)^{2},} \\
c_{v} & =\frac{s}{\bar{x}} \cdot 100 \%, \\
c_{i} & =\bar{x} \pm 1.96\left(\frac{s}{\sqrt{n}}\right) .
\end{aligned}
$$

Crack widths calculated by design provisions while evaluating the tension-stiffening effect and without it were overestimated with up to $85 \%$ (mean $32 \%$ ) and $86 \%$ (mean $40 \%$ ) errors $\left(\Delta=\left(1-w_{\exp } / w_{\text {calc }}\right) \cdot 100 \%\right)$, respectively. Besides, the coefficient of variation was very high, over $100 \%$; its scatter is 2 times higher than in the proposed method by the authors without evaluation of the influence of cross-sectional parameters and 5 times higher with it. Moreover, the proposed
TABLE 4: Statistical parameters of crack width estimation.

\begin{tabular}{lcccc}
\hline & $\begin{array}{c}w_{\text {calc }} \\
(\text { Eq. }(29), \\
(b, h)=1)\end{array}$ & $\begin{array}{c}w_{\text {calc }} \\
(\text { Eq. }(29), \\
\text { Eq. }(50))\end{array}$ & $\begin{array}{c}w_{\text {FIB }} \\
(\text { Eq. }(3))\end{array}$ & $\begin{array}{c}w_{\text {FIB2 }} \\
(\text { Eq. }(6))\end{array}$ \\
\hline $\bar{x}$ & 1.03 & 1.00 & 0.68 & 0.60 \\
$s$ & 0.53 & 0.22 & 0.70 & 0.64 \\
$c_{v}(\%)$ & 51.44 & 21.62 & 103.59 & 107.50 \\
$c_{i}$ & $0.83, \ldots, 1.23$ & $0.92, \ldots, 1.08$ & $0.41, \ldots, 0.95$ & $0.36, \ldots, 0.84$ \\
\hline
\end{tabular}

method in comparison with the design norms had a low average error $(3 \%, 0 \%)$, low standard deviation (0.53 and 0.22$)$, and low coefficient of variation $(51.44 \%$ and $21.62 \%)$, which led to the much better confidence intervals $\left(c_{i}\right)$. It means that the FRP-strengthened RC elements could be designed with more rational cross-sections and reinforcement ratios if the proposed methodology is being used.

3.4. Load-Carrying Capacity. Generally, the numerical calculations of the load-carrying capacity without reduction 


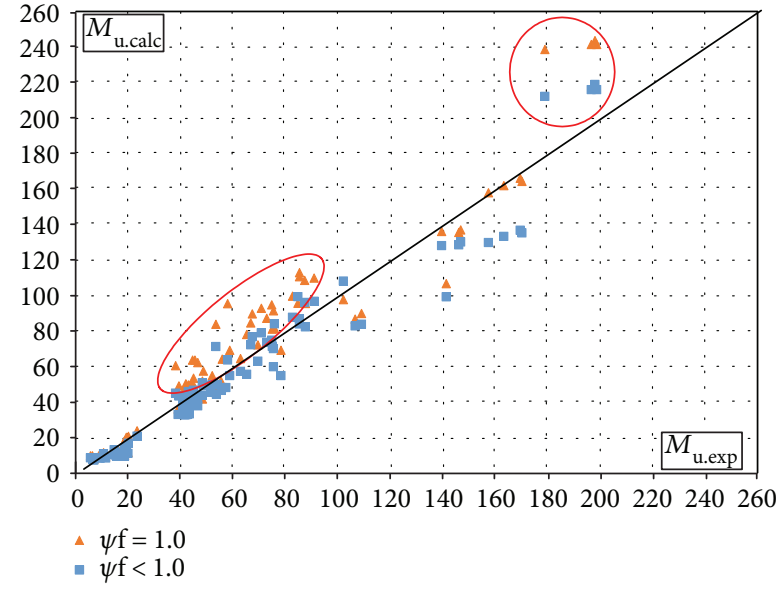

Figure 13: Comparison of experimental and numerical results of load-carrying capacity.

of FRP stress (due to the slippage between concrete and FRP, $\left.\psi_{f}=1.0\right)$ had lower mean error $(0 \%$ to $14 \%)$ but higher scatter (coefficient of variation $c_{v} 24.07 \%$ to $20.84 \%$ ). However, it should be noted that in some cases, the beams actually failed at loads close to $60 \%$ of the calculated ones (marked red in Figure 13) which is critically unsafe. Thus, it is vital to choose the correct calculation method. The main statistical parameters of the analysis are presented in Table 5.

The statistical parameters in Table 5:

$$
\begin{aligned}
x_{i} & =\frac{M_{\mathrm{u} . \text { exp. } \mathrm{i}}}{M_{\mathrm{u} . \text { calc. } \mathrm{i}}} \\
\bar{x} & =\frac{1}{n} \sum_{i=1}^{n} x_{i}, \\
s & =\sqrt{\frac{1}{n-1} \sum_{i=1}^{n}\left(x_{i}-\bar{x}\right)^{2}}, \\
c_{v} & =\frac{s}{\bar{x}} \cdot 100 \%, \\
c_{i} & =\bar{x} \pm 1.96\left(\frac{s}{\sqrt{n}}\right) .
\end{aligned}
$$

The analysis of experimental and numerical results proves that this calculation method allows the accurate evaluation of the load-carrying capacity of the normal section of flexural RC beams strengthened with FRP.

The proposed calculation method could be treated as appropriate for practical application when choosing the most effective strengthening material and when determining the crack width and load-carrying capacity of the strengthened member.

\section{Conclusions}

A crack width propagation and load-carrying capacity prediction model was presented in this paper. The conclusions
TABLE 5: Statistical parameters of load-carrying capacity.

\begin{tabular}{lcc}
\hline & $M_{\text {u.calc }}$ (Eq. $\left.(48), \psi_{f}=1.0\right)$ & $M_{\text {u.calc }}$ (Eq. $\left.(48), \psi_{f}<1.0\right)$ \\
\hline $\bar{x}$ & 1.00 & 1.14 \\
$s$ & 0.24 & 0.24 \\
$c_{v}(\%)$ & 24.07 & 20.84 \\
$c_{i}$ & $0.95, \ldots, 1.05$ & $1.09, \ldots, 1.19$ \\
\hline
\end{tabular}

of the analysis of experimental and numerical results are presented below.

(i) The crack width calculation techniques proposed in the design recommendations overestimate the crack width with up to $86 \%$ (average $32 \%$ and $40 \%$ ) error and very high scatter (coefficient of variation more than $100 \%)$.

(ii) The predicted crack widths by the proposed model agreed very well with experimental results (with $0 \%$ average error and a rather low coefficient of variation: $21.62 \%$ ), even for beams without additional anchorage and with initial strain (common situation in practice).

(iii) The crack propagation analysis revealed that prestressing of the strengthening material reduced the maximum crack width 2.67 times. This was evaluated in the proposed calculation method (calculated crack width of the non-prestressed beam was 2.55 times bigger than that of the prestressed one).

(iv) The propagation of cracks differs if the stiffness of the beams at the moment of strengthening is different. In the beams strengthened under external load action (with initial strain), the cracks had developed as in RC beams. After strengthening, further development of the cracks has slowed down, but the spacing remained the same. As a result, the crack widths of the beams strengthened under external load action (B5-7, B6-7) were 2 times higher than those strengthened without it (B3-0, B4-0). This validates the evaluation of the initial crack width in (29).

(v) The results of numerical calculations of the loadcarrying capacity without reduction of FRP stress (due to the slippage between concrete and FRP, $\left.\psi_{f}=1.0\right)$ had lower mean error ( $0 \%$ comparing to $14 \%$ ) but higher scatter (coefficient of variation $c_{v}$ equals to $24.07 \%$ and $20.84 \%$, resp.) than those with it. However, it should be noted that in some cases, the beams actually failed at loads close to $60 \%$ of the calculated ones which is critically unsafe. Thus, a calculation method with reduced FRP stress and a rather low (average 14\%) reserve could be treated as appropriate for the practical application when choosing the most effective strengthening material and when determining the load-carrying capacity of strengthened member. 


\section{Data Availability}

All data and results of a research are provided in the manuscript.

\section{Conflicts of Interest}

The authors declare that there is no conflict of interest regarding the publication of this paper.

\section{References}

[1] C. E. Bakis, L. C. Bank, V. L. Brown et al., "Fiber-reinforced polymer composites for construction-state-of-the-art review," Journal of Composites for Construction, vol. 6, no. 2, pp. 73-87, 2002.

[2] J. Valivonis, M. Budvytis, M. Atutis, E. Atutis, and L. Juknevičius, "Study on shear resistance of fiber-reinforced polymer-reinforced concrete beams," Advances in Mechanical Engineering, vol. 7, no. 7, 2015.

[3] M. Panjehpour, N. Farzadnia, R. Demirboga, and A. A. A. Ali, "Behavior of high-strength concrete cylinders repaired with CFRP sheets," Journal of Civil Engineering and Management, vol. 22, no. 1, pp. 56-64, 2015.

[4] L. Torres, I. A. Sharaky, C. Barris, and M. Baena, "Experimental study of the influence of adhesive properties and bond length on the bond behaviour of NSM FRP bars in concrete," Journal of Civil Engineering and Management, vol. 22, no. 6, pp. 808-817, 2016.

[5] M. Aktas and Y. Sumer, "Nonlinear finite element analysis of damaged and strengthened reinforced concrete beams," Journal of Civil Engineering and Management, vol. 20, no. 2, pp. 201-210, 2014.

[6] T. Skuturna, J. Valivonis, P. Vainiunas, G. Marciukaitis, and M. Daugevicius, "Analysis of deflections of bridge girders strengthened by carbon fibre reinforcement," The Baltic Journal of Road and Bridge Engineering, vol. 3, no. 3, pp. 145-151, 2008.

[7] M. Atutis, J. Valivonis, and E. Atutis, "Analysis of serviceability limit state of GFRP prestressed concrete beams," Composite Structures, vol. 134, pp. 450-459, 2015.

[8] Y. J. Kim, M. F. Green, and R. Gordon Wight, "Prestressed fiber-reinforced polymer (FRP) composites for concrete structures in flexure: fundamentals to applications," in Advanced Composites in Bridge Construction and Repair, Y. J. Kim, Ed., pp. 30-60, Woodhead Publishing, 2014.

[9] T. Skuturna and J. Valivonis, "Experimental study on the effect of anchorage systems on RC beams strengthened using FRP," Composites Part B Engineering, vol. 91, pp. 283-290, 2016.

[10] S. T. Smith and J. G. Teng, "FRP-strengthened RC beams. I: review of debonding strength models," Engineering Structures, vol. 24, no. 4, pp. 385-395, 2002.

[11] J. G. Teng, S. T. Smith, J. Yao, and J. F. Chen, "Intermediate crack-induced debonding in RC beams and slabs," Construction and Building Materials, vol. 17, no. 6-7, pp. 447-462, 2003.

[12] J. Valivonis and G. Marčiukaitis, "Technological-structural peculiarities of reinforced concrete structures strengthened with carbon fiber-reinforced polymer," Technological and Economic Development of Economy, vol. 12, no. 2, pp. 77-83, 2006.
[13] G. Marchukaitis, Y. Valivonis, and J. Bareishis, "An analysis of the joint operation of a CFRP concrete in flexural elements," Mechanics of Composite Materials, vol. 43, no. 5, pp. 467478, 2007.

[14] M. Daugevicius, J. Valivonis, and G. Marciukaitis, "Deflection analysis of reinforced concrete beams strengthened with carbon fibre reinforced polymer under long-term load action," Journal of Zhejiang University SCIENCE A, vol. 13, no. 8, pp. 571-583, 2012.

[15] J. Valivonis and T. Skuturna, "Cracking and strength of reinforced concrete structures in flexure strengthened with carbon fibre laminates," Journal of Civil Engineering and Management, vol. 13, no. 4, pp. 317-323, 2007.

[16] T. Skuturna, Research of flexural reinforced concrete members strengthened with external carbon fibre, $\mathrm{PhD}$ Thesis, Vilnius Gediminas Technical University, Lithuania, 2009.

[17] T. Skuturna and J. Valivonis, "Design method for calculating load-carrying capacity of reinforced concrete beams strengthened with external FRP," Construction and Building Materials, vol. 50, pp. 577-583, 2014.

[18] EN 1992-1-1:2004, "Eurocode 2: Design of concrete structure-part 1-1: general rules and rules for buildings," European standard, European Committee for Standardization (CEN), 2004.

[19] Fib bulletin 14, "Externally bonded FRP reinforcement for RC structures," Technical report, 2001.

[20] C. Miàs, L. Torres, M. Guadagnini, and A. Turon, "Short and long-term cracking behaviour of GFRP reinforced concrete beams," Composites Part B: Engineering, vol. 77, pp. 223-231, 2015.

[21] F. Ceroni and M. Pecce, "Design provisions for crack spacing and width in RC elements externally bonded with FRP," Composites: Part B, vol. 40, no. 1, pp. 17-28, 2009.

[22] M. Zomorodian, G. Yang, A. Belarbi, and A. Ayoub, "Cracking behavior and crack width predictions of FRP strengthened RC members under tension," Engineering Structures, vol. 125, pp. 313-324, 2016.

[23] V. Jokūbaitis and L. Juknevičius, "Critical depth of normal cracks in reinforced concrete beams of rectangular crosssection," Journal of Civil Engineering and Management, vol. 19, no. 4, pp. 583-590, 2013.

[24] V. Jokūbaitis, L. Juknevičius, and R. Šalna, "Conditions for failure of normal section in flexural reinforced concrete beams of rectangular cross-section," Procedia Engineering, vol. 57, pp. 466-472, 2013.

[25] V. Jokūbaitis and Z. Kamaitis, Gelžbetoniniu konstrukciju pleišejimas ir remontas [Cracking and repair of reinforced concrete structures], p. 156, Technika, Vilnius, Lithuania, 2000.

[26] V. Jokūbaitis, Statybiniu medžiagu ir konstrukciju irimo mechanikos pagrindai [Basics of fracture mechanics of building materials and constructions], p. 92, Technika, Vilnius, Lithuania, 2001.

[27] V. Jokūbaitis, "Peculiarities of methods for calculation of normal crack width in reinforced concrete members," in Selected Papers of Conference "Statybines konstrukcijos", vol. 6, pp. 73-84, Vilnius, Lithuania, February 2009.

[28] V. Jokūbaitis and L. Juknevičius, "Gelžbetoninių konstrukcijų normalinių plyšių pločio skaičiavimo metodų analizèAnalysis of methods for calculating the width of normal cracks in reinforced concrete structures," Statybines konstrukcijos ir technologijos, vol. 1, no. 1, pp. 23-29, 2009. 
[29] E. Dulinskas, D. Zabulionis, and R. Balevičius, “A composition of equivalent compressive stress diagrams for strength analysis of flexural reinforced concrete elements," in Selected Papers of Conference "Statybines konstrukcijos", vol. 6, pp. 5-11, Vilnius, Lithuania, February 2009.

[30] J. Slaitas, J. Valivonis, L. Juknevičius, and R. Šalna, "Load-bearing capacity of flexural reinforced concrete members strengthened with fiber-reinforced polymer in fracture stage," Advances in Mechanical Engineering, vol. 10, no. 5, 2018.

[31] J. Slaitas, Z. Hlavac, and A. Šneideris, "Flexural reinforced concrete elements normal section bearing capacity evaluation in fracture stage," Engineering Structures and Technologies, vol. 9, no. 2, pp. 70-78, 2017.

[32] H. Peng, J. Zhang, C. S. Cai, and Y. Liu, “An experimental study on reinforced concrete beams strengthened with prestressed near surface mounted CFRP strips," Engineering Structures, vol. 79, pp. 222-233, 2014.

[33] W.-T. Jung, Y.-H. Park, J.-S. Park, J.-Y. Kang, and Y.-J. You, "Experimental investigation on flexural behavior of RC beams strengthened by NSM CFRP reinforcements," in SP-230: 7th International Symposium on Fiber-Reinforced (FRP) Polymer Reinforcement for Concrete Structure, pp. 795-806, Kansas City, Missouri, November 2005.

[34] W. T. Jung, J. S. Park, J. Y. Kang, and M. S. Keum, "Flexural behavior of concrete beam strengthened by near-surface mounted CFRP reinforcement using equivalent section model," Advances in Materials Science and Engineering, vol. 2017, Article ID 9180624, 16 pages, 2017.

[35] S. K. Woo, J. W. Nam, J. H. J. Kim, S. H. Han, and K. J. Byun, "Suggestion of flexural capacity evaluation and prediction of prestressed CFRP strengthened design," Engineering Structures, vol. 30, no. 12, pp. 3751-3763, 2008.

[36] B. Fu, G. M. Chen, and J. G. Teng, "Mitigation of intermediate crack debonding in FRP-plated RC beams using FRP U-jackets," Composite Structures, vol. 176, pp. 883-897, 2017.

[37] I. A. Sharaky, L. Torres, J. Comas, and C. Barris, "Flexural response of reinforced concrete (RC) beams strengthened with near surface mounted (NSM) fibre reinforced polymer (FRP) bars," Composite Structures, vol. 109, pp. 8-22, 2014.

[38] I. A. Sharaky, L. Torres, and H. E. M. Sallam, "Experimental and analytical investigation into the flexural performance of RC beams with partially and fully bonded NSM FRP bars/ strips," Composite Structures, vol. 122, pp. 113-126, 2015.

[39] R. El-Hacha and M. Gaafar, "Flexural strengthening of reinforced concrete beams using prestressed, near-surfacemounted CFRP bars," PCI Journal, vol. 56, no. 4, pp. 134151, 2011.

[40] J. A. O. Barros and A. S. Fortes, "Flexural strengthening of concrete beams with CFRP laminates bonded into slits," Cement and Concrete Composites, vol. 27, no. 4, pp. 471-480, 2005.

[41] M. Rezazadeh, I. Costa, and J. Barros, "Influence of prestress level on NSM CFRP laminates for the flexural strengthening of RC beams," Composite Structures, vol. 116, pp. 489-500, 2014. 


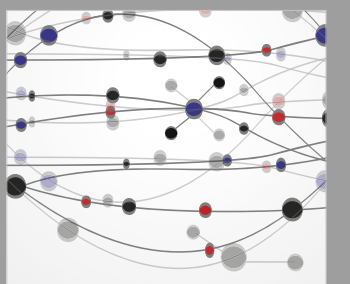

The Scientific World Journal
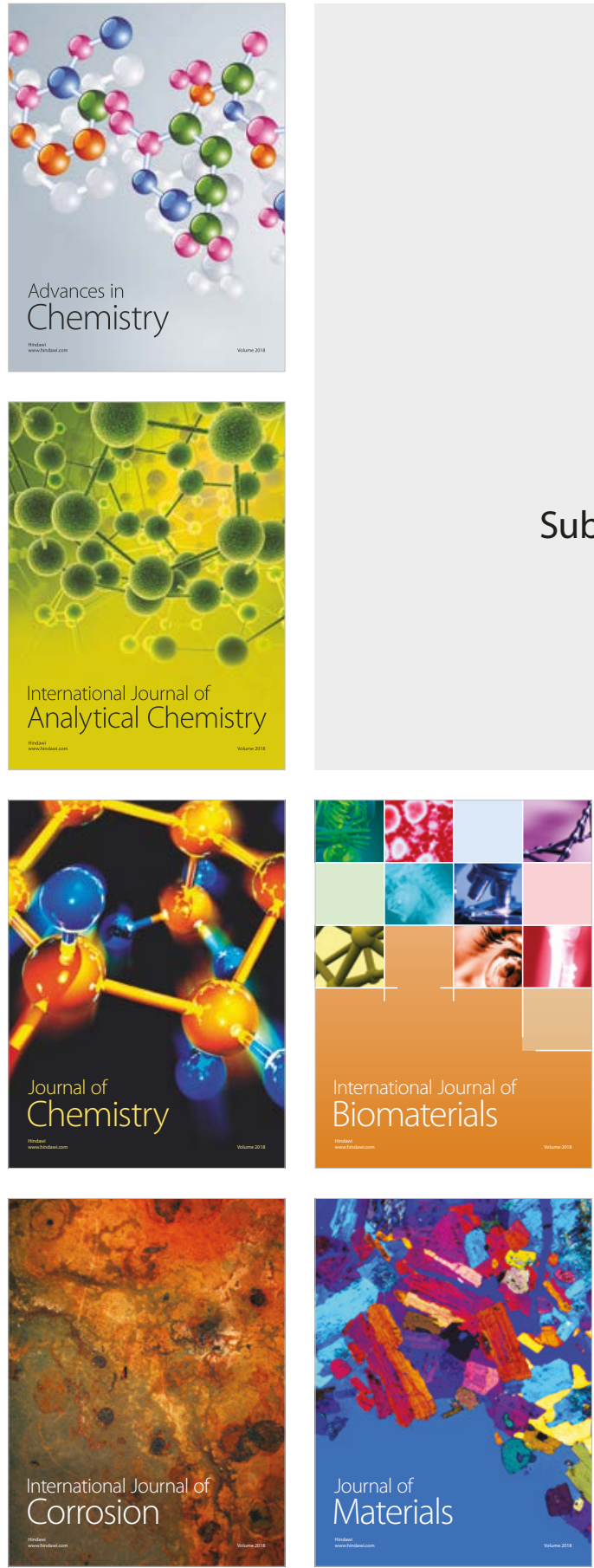

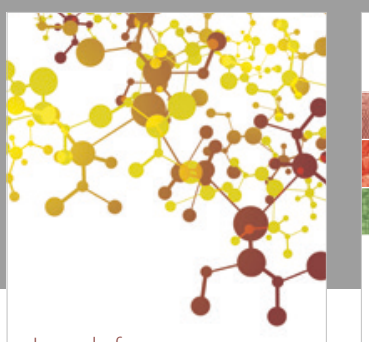

Journal of

Applied Chemistry
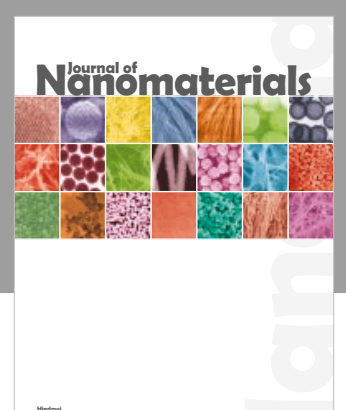

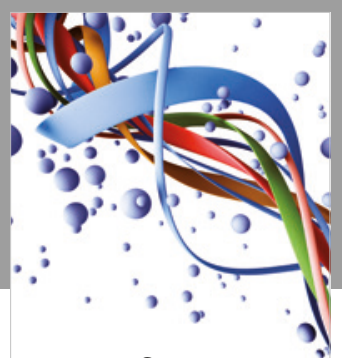

Scientifica

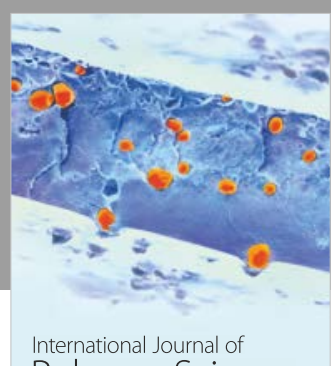

Polymer Science

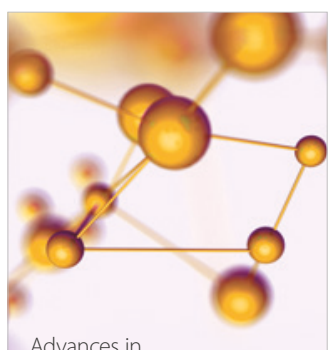

Physical Chemistry
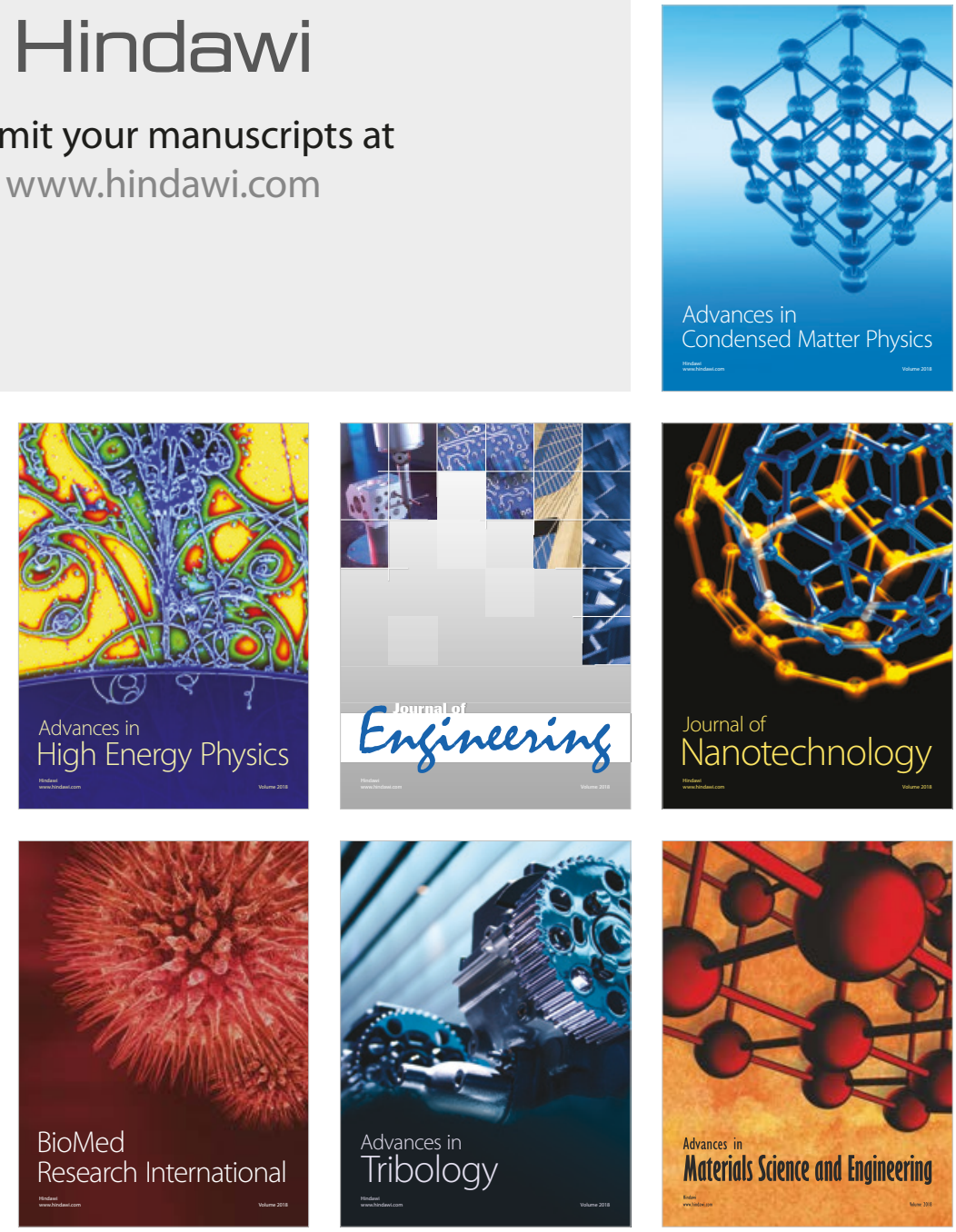